\title{
Tingkat Kepuasan Pasien Rawat Jalan Terhadap Pemberian Informasi Obat (Pio) Diinstalasi Farmasi Rawat Jalan RSUD Curup Rejang Lebong
}

\author{
Listiana Oktawilova ${ }^{1}$, NoriWirahmi ${ }^{1}$, Maiyulis ${ }^{2}$ \\ Prodi D3 Farmasi FMIPAUniversitas Bengkulu \\ Prodi D3Keperawatan FMIPA Universitas Bengkulu \\ Email:maiyulis@unib.ac.id
}

\begin{abstract}
ABSTRAK
Pemberian informasi Obat (PIO) merupakan kegiatan penyediaan dan pemberian informasi rekomendasi obat yang independen, akurat, tidak bias, terkini dan komprehensif yang dilakukan oleh apoteker. Pelayanan yang didapat dalam instalasi farmasi rumah sakit dapat berupa interaksi dengan pelayanan medis, pasien, sistem pelayanan kesehatan secara keseluruhan seperti adiminitrasi, keuangan, pelayananin formasi obat, waktu tunggu obat, sert tenaga kesehatan. Tujuan penelitian untuk mengetahui tingkat kepuasan pasien rawat jalan terhadap pemberian Informasi Obat di Instalasi Farmasi RSUD Curup Rejang Lebong Berdasarkan survey awal yang dilakukan peneliti terhadap 8 pasien yang telah menebus obat di Instalasi Farmasi RSUD Curup, mengenai bagai manakah pelayanan informasiobat diRSUD Curup, didapat kan hasil dengan penilaian tidak puas yang didapat sebanyak 5 orang dan puas 3 orang untuk pelayanan informasi obat di Instalasi Farmasi RSUD Curup. Jenis penelitian yang digunakan pada penelitia ini adalah deskriptif analitik dengan jumlah sampel 98 orang di instalasi farmasi rawat jalan RSUD Curup pada tanggal 1-30 April 2019. Data dianalisis secara univariat. Hasil penelitian menunjukkan 48\% responden tidak puas, $32,7 \%$ responden puas terhadap pemberian informasiobat (PIO), 19,3\% responden sangat puas terhadap pemberian informasi obat(PIO) di instalasi farmasi rawat jalan RSUD Curup Rejang Lebong.
\end{abstract}

Kata kunci: PIO,Tingkat Kepuasan

\section{PATIENT SATISFACTION LEVEL WITH PATIENT INFORMATION SERVICES (PIO) IN PHARMACY DEPATEMENT AT RSUD CURUP REJANG LEBONG}

\begin{abstract}
Provision of Drug Information (PIO) is an activity to provide and provide information on drug recommendations that are independent, accurate, unbiased, up to date and comprehensive carried Out by pharmacists. Services obtained in hospital pharmacy installations can be in the formof interactions with medical services, patients, the overall health care system such asadministration, finance, drug information services, drug waiting times, and health workers. The aim of the study was to find out thelevel of out patient satisfaction with theprovision of drug information at the harmacy Installationin RSUD Curup Rejang Lebong. Based on the initial survey conducted by researchers on 8 patients who had redeemed medicineat Curup Hospital Pharmacy Installation, regarding how the drug information service in Curup Hospital was obtained with adissatisfied assessment obtained as many as 5 peoplean dsatisfied 3 people to service drug information in CurupHospitalPharmacy Installation. The type ofresearch used in this study was descriptive analytic with asample of 98people at outpatient pharmacy installation at CurupHospital on April 1-30,2019. Data were analyzed univariately. Theresults showed $48 \%$ of respondents were dissatisfied,32.7\% of respondents were satisfie dwith thep rovisionof drug information(PIO), $19.3 \%$ of respondents were very satisfied with the provision of drug information (PIO) at out patient pharmacy installation at Curup Rejang Lebong Hospital. Conclusions, almost all respondents were dissatisfied with thep rovision of drugi nformation at the out patient pharmacy in stallation at Curup Rejang Lebong Hospital.
\end{abstract}

Keywords: PIO, Satisfaction Level 


\section{Pendahuluan}

Kepuasan pasien menjadi bagian yang integral dan menyeluruh dari kegiatan layanan kesehatan, artinya pengukuran tingkat kepuasan pasien menjadi kegiatan yang tidak dapat dipisahkan dari layanan kesehatan . Kepuasan pasien dalam menggunakan jasa instalasi farmasi merupakan cerminan hasil dari mutu. Pelayanan kesehatan yang diberikan di instalasi farmasi. Pelayanan tersebut dapat berupa interaksi dengan pelayanan medis, pasien, sistem pelayanan kesehatan secara keseleruhan seperti adiminitrasi, keuangan, pelayanan informasi obat, waktu tunggu obat, serta tenaga kesehatan.

Pelayanan yang didapat dalam Instalasi Farmasi Rumah Sakit dapat berupa interaksi dengan Pelayanan medis, pasien, sistem pelayanan kesehatan secara keseleruhan seperti adiminitrasi, keuangan, pelayanan informasi obat, waktu tunggu obat, serta tenaga kesehatan. Pelayanan informasi obat didefinisikan sebagai kegiatan penyediaan dan pemberian informasi, rekomendasi obat yang independen, akurat, komprehensif, terkini oleh apoteker kepada pasien, masyarakat maupun pihak yang memerlukan di rumah sakit. Pelayanan informasi obat meliputi penyediaan, pengolahan, penyajian, dan pengawasan mutu data atau informasiobatdan keputusan professional Pelayanan informasi obat harus benar, jelas, mudah dimengerti, akurat, tidak bias, etis,bijaksana, dan terkini sangatdiperlukan dalam upayąpenggunaanobatyang rasional. Oleh pasien ${ }^{3}$.Hal-halyang termasuk dalam Informasi Obat meliputi dosis, bentuk sediaan, formulasi khusus, rute dan metode pemberian, farmako kinetik, farmakologi, terapeutik danalternative, efikasi, keamanan penggunaan pada ibu hamildan menyusui, efek samping, inteaksi , stabilitas, ketersediaan, harga ,sifat Fisika atau kimia dari obat dan lain-lain. Tujuan penelitian untuk mengetahui tingkat kepuasan pasien rawat jalan terhadap Pelayanan Informasi Obat diInstalasi FarmasiRSUD Curup Rejang Lebong.

\section{Metode Penelitian}

Jenis penelitianini adalah penelitian Deskriptif. Penelitian deskriptif merupakan metode yang digunakan untuk mendeskripsikan atau menggambarkan suatu gambaran secara sistematis, faktual dan akurat mengenai fakta-fakta, sifat-sifat serta hubungan antar fenomena yang diselidiki ${ }^{5}$. Penelitian dilakukan diInstalasi Farmasi Rawat Jalan RSUD Curup Kabupaten Rejang Lebong selama satu bulan terhitung sejak tangga 15April-5 Mei 2019. Populasiyang digunakan dalam penelitian ini adalah pasien yang datang keinstalasi farmasi RSUD Curup Rejang Lebong berjumlah 3.251 orang. Berdasarkan hasil perhitungan sampel dapat diketahui bahwa banyaknya responden yang akan diteliti sebanyak 98 orang.

\section{Hasil Penelitian}

\section{KarakteristikResponden}

Karakteristik responden dalam penelitian ini dilihat dari tingkat pendidikan, jenis kelamin, jenis pekerjaan.

Tabel 1. Karakteristik Responden Berdasarkan Pendidikan, Pekerjaan, Jenis Kelamin di Unit Farmasi RSUD. Curup Kabupaten Rejang Lebong tahun 2019

\begin{tabular}{|l|l|l|}
\hline $\begin{array}{l}\text { Karakteristik } \\
\text { Responden }\end{array}$ & $\mathrm{F}$ & $\%$ \\
\hline $\begin{array}{l}\text { Pendidikan } \\
\text { tinggi } \\
\text { SMA }\end{array}$ & 21 & 22 \\
SLTP & 51 & 52 \\
SD & 10 & 10 \\
\hline Jumlah & 98 & 100 \\
\hline $\begin{array}{l}\text { Jenis kelamin } \\
\text { Laki-laki }\end{array}$ & 65 & 66 \\
\hline $\begin{array}{l}\text { Jenis kelamin } \\
\text { perempuan }\end{array}$ & 33 & 34 \\
\hline Jumlah & 98 & 100 \\
\hline
\end{tabular}




\begin{tabular}{|l|l|l|}
\hline PNS & 21 & 22 \\
\hline Wirasta & 11 & 11 \\
\hline Swasta & 14 & 14 \\
\hline Petani & 21 & 22 \\
\hline $\begin{array}{l}\text { Ibu Rumah } \\
\text { Tangga }\end{array}$ & 31 & 31 \\
\hline Jumlah & 98 & 100 \\
\hline
\end{tabular}

Berdasarkan tabel 1 diketahui bahwa dari 98 orang responden terdapat 51 (52\%) responden berpendidikan SMA, dan 16 (16\%) responden berpendidikan sekolah dasar(SD). Berdasarkan jenis kelamin diketahui $65(66 \%)$ berjenis kelamin perempuan, berdasarkan pekerjaan terdapat $31 \quad(31 \%)$ bekerja sebagai iburumah tangga.

Tabel 2. Analisis Tingkat Kepuasan berdasarkan dimensi reliability (keandalan) di Unit Farmasi RSUD. Curup Kabupaten Rejang Lebong tahun 2019

\begin{tabular}{lll}
\hline $\begin{array}{l}\text { Tingkat } \\
\text { kepuasan }\end{array}$ & Jumlah & $\begin{array}{l}\text { Persen } \\
(\%)\end{array}$ \\
\hline $\begin{array}{l}\text { Tidak } \\
\text { puas }\end{array}$ & 48 & 49 \\
Puas & 24 & 34,7 \\
$\begin{array}{l}\text { Sangat } \\
\text { puas }\end{array}$ & 16 & 16,3 \\
\hline & 98 & 100 \\
\hline
\end{tabular}

Berdasarkan tabel 2, dari 98 responden terdapat 48 orang $(49 \%)$ responden menyatakan tidak puas terhadap dimensi reliability dan 16 (16,3\%) orang, menyatakan sangat puas.

Tabel 3.Analisis Tingkat Kepuasan berdasarkan dimensi responsivenes(ketanggapan) di Unit Farmasi RSUD. Curup Kabupaten Rejang Lebong tahun 2019

\begin{tabular}{lll}
\hline $\begin{array}{l}\text { Tingkat } \\
\text { kepuasan }\end{array}$ & Jumlah & $\begin{array}{l}\text { Persen } \\
(\%)\end{array}$ \\
\hline Tidak & 50 & 51 \\
\hline
\end{tabular}

\begin{tabular}{lcc}
\hline puas & & \\
Puas & 34 & 34,7 \\
$\begin{array}{l}\text { Sangat } \\
\text { puas }\end{array}$ & 14 & 14,3 \\
\hline & 98 & 100 \\
\hline
\end{tabular}

Berdasarkan tabel 3. diatas tingkat kepuasan responden berdasarkan dimensi responsiveness dari 98 responden terdapat $50 \quad(51 \%)$ responden menyatakan tidak puas dan $14(14,3 \%)$ responden menyatakan sangat puas

Tabel 4.Analisis Tingkat Kepuasan berdasarkan dimensi Assurance (jaminan) di . Unit Farmasi RSUD. Curup Kabupaten Rejang Lebong tahun 2019

\begin{tabular}{lll}
\hline $\begin{array}{l}\text { Tingkat } \\
\text { kepuasan }\end{array}$ & Jumlah & $\begin{array}{l}\text { Persen } \\
(\%)\end{array}$ \\
\hline $\begin{array}{l}\text { Tidak } \\
\text { puas }\end{array}$ & 49 & 50 \\
Puas & 28 & 28,6 \\
$\begin{array}{l}\text { Sangat } \\
\text { puas }\end{array}$ & 21 & 21,4 \\
\hline & 98 & 100 \\
\hline
\end{tabular}

Berdasakan tabel 4. Diatas tingkat kepuasan responden berdasarkan dimensi assurance dari 98 responden terdapat 50 orang (49\%) responden menyatakan tidak puas, dan sebanyak 21 orang $(21,4 \%)$ responden sangat puaspemberian informasi obat dalam dimensiemphaty.

Tabel 5. Analisis Tingkat Kepuasan berdasarkan dimensi emphaty di Unit Farmasi RSUD. Curup Kabupaten Rejang Lebong tahun 2019

\begin{tabular}{lll}
\hline Tingkat & Jumlah & Persen (\%)
\end{tabular}




\begin{tabular}{lll}
\hline kepuasan & & \\
\hline $\begin{array}{l}\text { Tidak } \\
\text { puas }\end{array}$ & 48 & 49 \\
Puas & 21 & 21,4 \\
$\begin{array}{l}\text { Sangat } \\
\text { puas }\end{array}$ & 29 & 29,6 \\
\hline & 98 & 100 \\
\hline
\end{tabular}

Berdasarkan tabel 5. diatas tingkat kepuasan responden berdasarkan dimensi emphaty dari 98 responden terdapat 48 (49\%) responden menyatakan tidak puas dan 21 $(21,4 \%)$ responden menyatakan s puas .

\section{PEMBAHASAN}

Hasil penelatian berdasar kan Tabel 2. didapatkan bahwa dari 98 responden terdapat $16,3 \%$ responden menyatakan sangat puas terhadap pelayanan dilihat dari dimensi reability (keandalan). Hal ini terjadi karena sumber daya manusia yang ada di instalasi rawat jalan RSUD Curup cukup untuk melayani pasien dalam pemberian obat. Dimana di Instalasi farmasi rawat jalan terdapat 1 orang apoteker dan 3 tenaga teknis kefarmasian bagianpelayanan resep, 2 orang tenaga kefarmasian bagian enty resep.

Berdasarkan hasil penelitian dan observasi diketahui terdapat hari - hari tertentu dimana jumlah pasien sebanding dengan jumlah sumber daya manusia yang ada sehingga dalam melayani pasien terutama dalam pelayanan pemberian informasi obat dapat dilakukan dengan maksimal. Penyampaian informasi obat dilakukan oleh tenaga kefarmasian dengan jelas dan cepat dalam menanggapi pertanyaan yang diberikan oleh pasien. Hal ini lah yang membuat pasien merasa sangat puas terhadap pelayanan pemberian informasi obat.

Suatu perusahaan atau rumah sakit sangat tergantung pada sumber daya manusia (SDM). Pengetahuan dan keahlian yang dimiliki petugas sangat penting bagi perusahaan atau rumah sakit untuk memenuhi harapan pelanggan (pasien) dalam strategi pelayanan yang diberikan. Sumber daya manusia farmasi rumah sakit dapat mempengaruhi kualitas pelayanan farmasi dirumah sakit, berdasarkan penyelenggaraan pelayanan kefarmasian dilaksanakan oleh tenaga farmasi professional yang berwenang berdasarkan undang-undang memenuhi syarat baik dari segi aspek hukum, strata pendidikan, kualitas maupun kuantitas dengan jaminan kepastian adanya peningkatan pengetahuan, keterampilan dan sikap eprofesionalanterusmenerus dalam rangka menjaga mutu profesi dankepuasan pelanggan ${ }^{7}$. Hasil peneltian juga sesuai dengan penelitian yang dilakukan oleh Harianto di Jakarta padat tahun 2005 dengan judul"Kepuasan pasien terhadap pelayanan resep di Apotek Kopkar Rumah Sakit Budhi Asih Jakarta".Pasien Apotek Kopkar sangat puas terhadap keramahan petugas, dan kebersihan ruang tunggu, pasien juga cukup puas terhadap kecepatan pelayanan obat, kecepatan pelayanan kasir, kelengkapaninformasi obat, kemurahan pelayanan obat, kecukup an tempat duduk, dan kenyamanan ruang tunggu dan kipas angin dan $\mathrm{AC}$, dan pasien cukup puas terhadap ketersediaan televisi ${ }^{8}$. Salah satu factor yang mempengaruhi kepuasaan adalah kualitas pelayanan terhadap pasien. Pasien akan merasa puas bila mereka mendapatkan pelayanan yang baik, ramah dan sesuai dengan yang diharapkan. Harapan masyarakat sekarang apabila berobat di pelayanan kesehatan, selain 
mengharapkan lebih dari sekedar suatu pengobatan yang tepat,juga mereka inginmerasakan kepuasan dalam hal pelayanan petugas yang profesional, ramah, ikhlas, bermutu dan antusias, termasuk pelayanan informasi obat $^{9}$. Pelayanan kesehatan dipandang baik karena petugasnya ramah, bersahabat, sabar, dan komunkastif, sebaliknya jika pelayanan kesehatan dianggap kurang baik karena petugasnya kasar dan berbica kurang sopan 10 .

Tingkat kepuasan pasien dapat diukur melalui keramahan pegawai. Pentingnya bagi instalasi farmasi rumah sakit untuk memberikan jaminan yang baik kepada pasien terhadap pelayanan dalam pemberian informasiobat dengan memberikan obatyang tepat sesuai dengan kebutuhan pasien.

Pemberian informasi tentang indikasi, cara pakai, dan efek samping obat juga ikut memberikan andil dalam meningkatkan kepuasan pasien ${ }^{11}$. Tenaga kefarmasian harus memberikan informasi obat yang benar, jelas dan mudah dimengerti, akurat, tidak bias, etis, bijaksana dan terkini. Informasi obat yang diserah kanoleh tenagapenyerahobat (drug dispenser) kepada konsumen disebut berkualitas apabila informasi mencakup keterangan mengenai obat yang mencakup komponen informasi utama tentang obat.

Standar Pelayanan Farmasi di RumahSakit yang telah ditetapkandalam SK Menkes Nomor 1197/Menkes/SK/X/2004 merupakan parameter yang digunakan untuk menilai kualitas pelayanan informasi obat dan macam informasi obatyang disampaikan oleh petugas penyerah obat di instalasi farmasi. Pelayanan informasi obat dari Apoteker kepadapasien belum maksimal dikarenakan waktu pelayanan informasi obat yang terbatas dan informasi obat yang diberikan tidak menjelaskan semua hal tentang obat yang digunakan oleh pasien. Pentingnya memberikan informasi yang jelas tentang penyakitnya kepada pasien juga akan mempengaruhi kepuasan pasien terhadap kesehatan, karna kepuasan pasien akan tercapai apabila diperoleh hasi loptimal bagi pasien dalam pelayanan kesehatan dengan memperhatikan kemampuan pasien dan keluarga. Perhatian antara kebutuhan pasien tercapai keseimbangan sebaikbaiknya antara rasa puas dan tidak puas. Ketidak puasan yang dirasakanoleh responden memberikan dampak terhadap instalasi farmasi rawat jalan dimana jumlah kunjungan pasien yang mengambil obat diinstalasi farmasi rawat jalan setiap bulan mengalami penurunan. Hal ini akan memberikan dampak pada pendapatan bagi instalasi farmasi maupun bagipihak RSUD Curup Rejang Lebong. Oleh karena itu untukmeningkatkankualitas dalam pelayananpemberian informasi obat diinstalasifarmasirawatjalan harus dilakukan berbagai upaya seperti menambah sumber daya manusia sehingga beban kerja dapat berkurang dan petuga skefarmasian dapat memberikan pelayanan dengan optimal, selain itu pemberian promosi kesehatan tentang obat dilakukan setiap minggunya dan pemasanganbarnerataupun poster tentang informasi obat dapat dipasang disetiapruang tunggu pada instalasifarmasirawatjalan sehingga pasien mengerti dan memahami informasi apa saja yang harus diketahui oleh mereka.

\section{Simpulan}

Berdasar kanpenelitian yang dilakukan diInstalasi Farmasi RSUD Curup maka didapatkan hasil yaitu : Sebanyak $\quad 49 \% \quad$ responden menyatakan tidak puasterhadap dimensireliability atau kehandalan padapemberian informasi obat (PIO), Sebanyak $\quad 51 \% \quad$ responden menyatakan tidak puasterhadap dimensi responsiveness pada pemberian informasi obat (PIO), Sebanyak $\quad 49 \% \quad$ responden menyatakan tidak puasterhadap dimensiassurance pada pemberian informasi obat (PIO), Sebanyak $49 \%$ responden menyatakan tidak puas terhadap dimensi emphaty pada pemberian informasi obat (PIO), 
Sebanyak $48 \%$ responden tidak puas terhadapa pelayanan dimensi empaty

\section{Daftar Pustaka}

Ingga.2011.Analisis Hubungan Tingkat

Kepuasan pasien Rawat Jalan Terhadap Pelayanan Instalasi Farmasi Dengan

Minat Pasien Menebus Kembali Resep Obat di Instalasi Farmasi RSUD BudhiAsih2010[tesis] .Jakarta:

UniversitasIndonesia.

Harianto, Khasana Nana, dan Supardi Sudibyo. 2005. Kepuasan pasien terhadap pelayanan resep di apotek kopkar rumah sakit budhi Jakarta. Diakes dari

https://www.google.com/search.

Pohan,Imbalo.S.2007.Jaminan Mutu Pelayanan Kesehatan: Dasar-dasar Pengertian dan Penerapan . EGC :Jakarta.

Pradono,J.danSulistyowati,N.2014.

Hubungan antaraTingkat Pendidikan, Pengetahuan Tentang Kesehatan Lingkungan, Perilaku Hidup Sehat dengan Status Kesehatan: StudiKorelasi pada PendudukUmur10-24 tahundiJakartaPusat. Buletin Penelitian Sistem Kesehatan, Fakultas Farmasi Universitas Muhammadiyah Surakarta: Surakarta

PERMENKES RI. 2016. Peraturan Pemerintah Republik Indonesia No72 tahun 2016 tentang StandarPelayanan Kefarmasian di Rumah Sakit

Sugiyono. 2007. Metode Penelitian Kesehatan. Rineka Cipta:Jakarta.

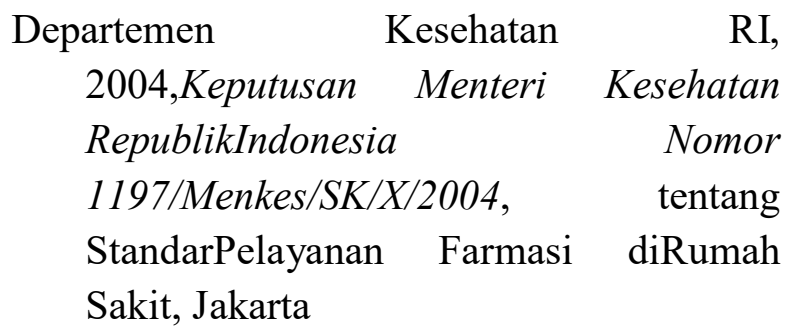


